\title{
KAJIAN EXPERIMENTAL PENGARUH VOID AGREGAT TERHADAP PROPERTIES BETON
}

\section{EXPERIMENTAL STUDY OF THE EFFECT OF AGGREGATE VOID ON CONCRETE PROPERTIES}

\author{
Mukti Agung Wibowo \\ Program Studi S1 Teknik Sipil, Fakultas Teknik dan Sains \\ Universitas Muhammadiyah Purwokerto
}

\section{Informasi Artikel}

Dikirim, 5 November 2021

Direvisi, 27 November 2021

Diterima, 31 Desember 2021

\section{Korespondensi Penulis:}

Mukti Agung Wibowo Program Studi Teknik Sipil Universitas Muhammadiyah Purwokerto

JL. K.H. Ahmad Dahlan Purwokerto, 53182

Email:

muktiagung8669@gmail.com

\section{ABSTRAK}

Campuran agregat dengan void minimal dalam perkerasan flexible memberikan distribusi beban yang baik kelapisan dibawahnya. Sehingga beban berat dapat di distribusikan dengan baik kelapisan bawahnya yang berkualitas lebih rendah. Penelitian dilakukan untuk mengetahui sejauh mana pengaruh agregat dengan void minimal pada propertis beton. Untuk komparasi propertis antara beton yang menggunakan agregat dengan void minimal terhadap beton tanpa memperhatikan void, dan beton yang menggunakan agregat dengan void maksimal digunakan acuan mix design Department of Environment. Pengaruh agregat dengan void minimal memberikan void beton lebihkecil, meningkatkan kuat tekan beton, dan meningkatkan kuat tarik belah betonnya dengan perbedaan yang tidak signifikan.

Kata Kunci : Void, Kuat Tekan, Kuat Tarik Belah

\section{ABSTRACT}

Aggregate mixture with minimum voids in flexible pavement provides good load distribution to the layer below it so that heavy loads can be distributed well to the layer below with lower quality. The research was conducted to determine the extent of the effect on aggregate with minimum voids in concrete properties. For the property comparison between the concrete using aggregates with minimum void to the concrete regardless of void, and the concrete using the aggregate with maximum void, it was used mix design Department of Environment. The effect of aggregate with minimum voids provided smaller concrete voids, increased the compressive strength of concrete, and increased the splitting tensile strength of concrete with no significant differences.

Keyword : voids, compressive strength, splitting tensile strength 


\section{PENDAHULUAN}

Campuran agregat dengan void minimal dalam perkerasan flexibel memberikan distribusi beban yang baik ke lapisan dibawahnya, karena kuat tekan beton merupakan salah satu kinerja utama yang dibutuhkan oleh beton. Beberapa faktor yang mempengaruhi kekuatan tekan beton antara lain: karakteristik agregat penyusun beton, kekuatan dan kebersihan agregat, faktor air semen, pengikatan dan pengerasan beton, porositas beton, suhu, bahan tambah ( admixture atau additive ), rongga udara ( void) dalam campuran agregat. Banyak hal yang dilakukan untuk mendapatkan kuat tekan beton yang tinggi, salah satunya yaitu dengan meninjau rongga udara dalam campuran agregat.Untuk mendapatkan rongga udara yang minimal dalam campuran agregat salah satunya dilakukan dengan cara optimasi void. Dalam penelitian ini akan dicoba peran void minimal dalam campuran beton untuk mengetahui pengaruh void minimal dalam campuran agregat terhadap void beton yang dilakukan dengan cara uji penyerapan ( absorpsi) beton, kuat tekan beton, dan kuat tarik belah beton.

Mendapatkan kuat tekan beton yang tinggi banyak hal yang dilakukan, salah satunya yaitu dengan meminimalkan rongga dalam campuran agregat. Rongga yang minimal diharapkan dapat meningkatkan kuat tekan beton dan penghematan kadar semen. Langkah yang dilakukan dalam penelitian ini yaitu dengan memilah diameter agregat kasar dan diameter agregat halus. Langkah yaitu melakukan optimasi void dengan cara uji experimental di laboratorium bahan dan kontruksi Teknik Sipil Universitas Diponegoro, Semarang.

Penelitian ini bertujuan untuk menentukan komposisi agregat yang menghasilkan void minimal, mengetahui sejauh mana pengaruh void agregat pada void beton, mengetahui sejauh mana beda propertis beton yang memiliki void minimal, beton dengan ketentuan DOE ( beton normal), dan beton dengan void maksimal ( beton dengan void terbesar yang masih menggunakan komposisi campuran agregat pasir, agregat 0,5-1, agregat 2-3).

\section{METODE PENELITIAN}

\subsection{Bahan dan Peralatan Penelitian}

Bahan dan penelitian pada penilitan ini sebagai berikut :

\begin{tabular}{ll}
\hline \multicolumn{1}{c}{ Bahan Penelitian } & \multicolumn{1}{c}{ Peralatan Penelitian } \\
\hline $\begin{array}{l}\text { 1. Semen Portland Type I (Semen Tiga Roda) } \\
\text { 2. Air }\end{array}$ & $\begin{array}{l}\text { Pada penelitian ini peralatan yang akan digunakan adalah } \\
\text { peralatan yang tersedia di laboratorium bahan kontruksi beton } \\
\text { Teknik Sipil Universitas Diponegoro, Semarang. }\end{array}$ \\
$\begin{array}{l}\text { 4. Agregat Kasar : (Split } 0.5-1 \mathrm{~cm} \text { Karangjati ) } \\
\text { ( Split } 2-3 \mathrm{~cm} \text { Karangjati ) }\end{array}$ & \\
\hline
\end{tabular}

\subsection{Pemilihan Agregat Halus dan Agregat Kasar}

Pemilihan agregat dilakukan untuk menentukan jenis agregat yang akan digunakan dalam penelitian ini, untuk material agregat halus menggunakan pasir Muntilan, sedangkan untuk material agregat kasar menggunakan batu pecah /split 0.5-1 cm dan 2-3 cm daerah Karangjati.

\subsection{Pengujian Agregat}

Pengujian agregat untuk mengetahui gradasi butiran agregat, agregat itu sendiri dibagi menjadi 2 yaitu agregat kasar dan halus. Agregat kasar menggunakan material split 0,5-1 dan split 2-3, sedangkan agregat halus menggunakan material pasir. Pengujian tersebut melalui 3 tahap diantaranya yaitu :

\section{Analisa Saringan}

Tujuan dilakukan analisa saringan yaitu untuk memperoleh distribusi besaran atau jumlah persentase butiran Bahan. Peralatan yang digunakan berupa timbangan dan satu set saringan. perhitungan analisa saringan sebagai berikut :
a. Persen Retained $=\frac{B}{A} \times 100 \%$
b. Persen Passing $=100 \%-\sum$ Persen Retained
$\mathrm{A}=$ berat benda uji kering oven ( gram ),
$\mathrm{B}=$ berat benda uji tertahan ayakan ( gram ).

\section{Berat Jenis}

Dilakukan pengujian berat jenis yaitu untuk mendapatkan angka atau nilai berat jenis agrega. Peralatan yang digunakan yaitu timbangan, oven, piknometer dengan kapasitas $500 \mathrm{ml}$. Perhitungan berat jenis agregat mengacu pada SNI 1970 - 2008 dan persamaan rumus : 


$$
\text { Berat jenis }=\frac{A}{(B+S-C)} \quad \begin{aligned}
& \mathrm{A}=\text { Berat benda uji kering oven }(\text { gram }) \\
& \mathrm{B}=\text { Berat piknometer yang berisi air }(\text { gram }) \\
& \mathrm{C}=\text { Berat piknometer dengan benda uji dan air sampai } \\
& \quad \text { batas pembacaan }(\text { gram }) \\
& \mathrm{S}=\text { Berat benda uji kondisi jenuh kering permukaan } \\
& \quad(\text { gram })
\end{aligned}
$$

\section{Berat Isi}

Pengujian berat isi dilakukan untuk menentukan berat isi agregat yang didefinisikan sebagai perbandingan antara berat material kering dengan volumenya. perhitungan berat isi agregat mengacu pada ASTM C29/C 29M - 97 dan persamaan rumus :

$$
\begin{array}{cl}
\mathrm{M}=(\mathrm{G}-\mathrm{T}) / \mathrm{V} & \mathrm{M}=\text { Berat isi agregat dalam kondisi kering oven }\left(\mathrm{kg} / \mathrm{m}^{3}\right) \\
& \mathrm{G}=\text { Berat agregat dan penakar, }(\mathrm{kg}) \\
\text { atau } & \mathrm{T}=\text { Berat penakar, }(\mathrm{kg}) \\
\mathrm{M}=(\mathrm{G}-\mathrm{T}) \times \mathrm{F} & \mathrm{V}=\text { Volume penakar }\left(\mathrm{m}^{3}\right)
\end{array}
$$

\subsection{Membuat Rencana Komposisi Beton}

Membuat rencana komposisi beton dengan perbandingan air semen (FAS ), agregat halus, agregat kasar dengan void minimal menggunakan metode DOE. perencanaan mix design dengan menggunakan metode DOE menggunakan porsentase pasir yang diperoleh dari uji optimasi campuran agregat gabungan. Setelah di plot dalam grafik yang ada dalam metode DOE, akan didapatkan nilai faktor air semen ( FAS ) yang nantinya dibuat sebagai acuan dalam perencanaan mix design.

\subsection{Pembuatan dan Perawatan Benda Uji Beton}

Pembuatan benda uji dilakukan untuk mendapatkan benda uji di laboratorium yang memenuhi persyaratan, sampel benda uji untuk beton dengan void minimal, beton normal, beton dengan void maksimal. Menggunakan 5 buah silinder untuk uji kuat tekan, 5 buah silinder untuk uji kuat tarik belah dan 3 buah silinder untuk uji absorpsi.

\subsection{Mencari Rongga Udara Dalam Beton}

Tujuan dilakukan pengujian untuk mengetahui nilai penyerapan beton dengan void minimal, penyerapan beton normal, dan penyerapan beton dengan void maksimal. perhitungan penyerapan pada beton mengacu pada ASTM C $642-97$ dengan persamaan rumus

$$
\begin{array}{lll}
\text { Penyerapan } & \begin{array}{l}
\mathrm{A}=\text { berat benda uji kering oven( gram ) } \\
\text { (Absorption) } \%
\end{array} \quad=[\text { ( B-A ) / A ] x 100 } & \mathrm{B}=\text { berat benda uji setelah direndam di air ( gram ) }
\end{array}
$$

\subsection{Perbandingan Pengujian Kuat Tekan, Kuat Tarik Belah}

Tujuan dilakukan pengujian untuk memperoleh nilai kuat tekan, nilai kuat tarik belah beton. Pengujian kuat tekan beton mengacu pada ASTM C39M - 01. Dan gambar pegujian kuat tekan sebagai berikut : 


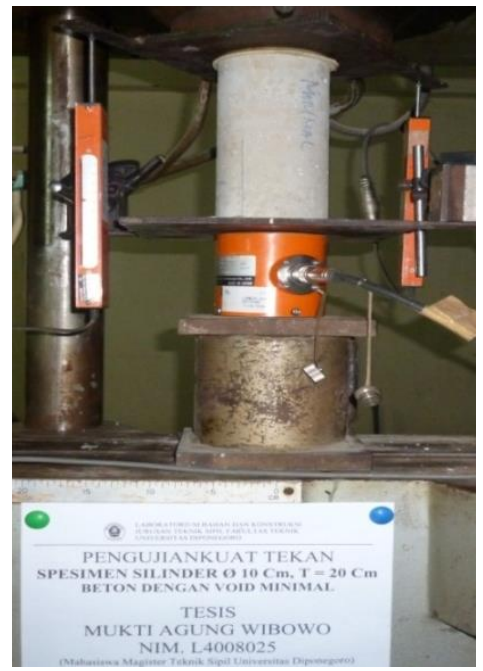

Gambar 1. Pegujian Kuat Tekan

Pengujian kuat tarik belah beton mengacu pada ASTM C496M - 04. Dan gambar pegujian kuat tarik belah sebagai berikut :

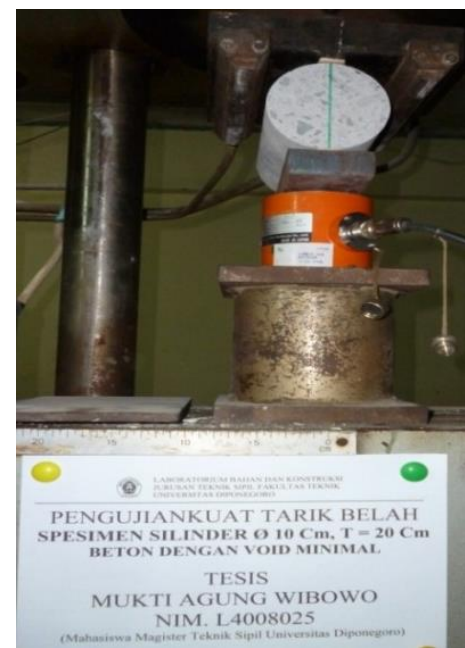

Gambar 2. Pegujian Kuat Tarik Belah

\section{HASIL DAN PEMBAHASAN}

Didapatkan analisa hasil penelitian sebagai berikut :

1. Penggunaan agregat 0,5-1, agregat 2-3 dan pasir dalam campuran agregat setelah dilakukan optimasi void maka menghasilkan rata - rata void minimal $26,85 \%$, sedangkan campuran agregat untuk beton normal menghasilkan void rata - rata 28,31\%. Perbedaan void ini sangat sedikit dikarenakan jarak antar diameter agregat kasar sangat kecil.

2. Perencanaan mix design menggunakan metode DOE dengan porsentase pasir yang sama dan dengan gradasi agregat kasar yang berbeda akan mengasilkan kuat tekan dan kuat tarik yang berbeda, ini dibuktikan dengan kuat tekan dan kuat tarik beton yang mempunyai void minimal lebih tinggi dibandingkan dengan beton normal dan beton yang mempunyai void maksimal.

3. Penyerapan pada beton dengan void minimal lebih rendah dibandingkan dengan beton normal dan beton dengan void maksimal. Walaupun perbedaanya yang tidak signifikan.

4. Peningkatan kuat tekan beton dan kuat tarik belah beton dipengaruhi oleh void beton, ini di buktikan dengan semakin menurun void beton maka kuat tekan dan kuat tarik belah beton semakin meningkat, sebaliknya semakin meningkat void beton maka kuat tekan dan kuat tarik belah beton semakin menurun. Dengan kecenderungan ( trendline ) yang sama dan digambarkan dengan kurva linier, untuk menondimensialkan grafik maka semua data dibagi dengan parameter pengujian, dalam hal ini parameter pengujian yaitu beton dengan ketentuan DOE ( beton normal). 


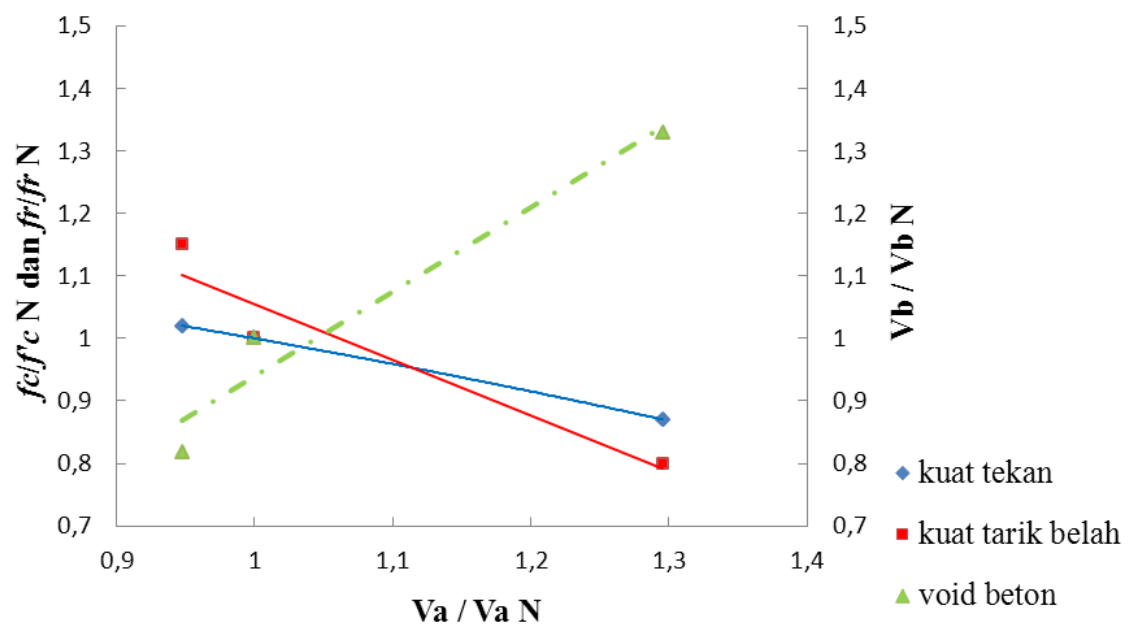

Grafik Hubungan Void agregat, kuat tekan, kuat tarik belah dan Void beton.

kuat tekan beton void minimal, beton void maksimal dibagi dengan kuat tekan beton normal $(f c /(f c \mathrm{~N}))$, kuat tarik belah beton void minimal, beton void maksimal dibagi dengan kuat tarik belah beton normal $(f r /(f r \mathrm{~N}))$, void beton minimal, void beton maksimal dibagi dengan void beton normal ( $\mathrm{Vb} /(\mathrm{Vb} \mathrm{N})$ ), void agregat minimal, void agregat maksimal dibagi dengan void agregat normal ( Va / Va N) dan grafik hubungan kuat tekan, kuat tarik belah beton, void agregat, dan void beton.

\section{KESIMPULAN}

Dari hasil penelitian yang telah dilakukan dapat disimpulkan sebagai berikut :

1. Dari optimasi void dengan komposisi campuran $13 \%$ agregat $0,5-1,52 \%$ agregat 2-3, dan $35 \%$ pasir mengahasilkan void minimal sebesar $26,85 \%$.

2. Penyerapan pada beton dengan void minimal lebih rendah dibandingkan beton normal dan beton dengan void maksimal, dengan perbedaan yang tidak signifikan.

3. Kuat tekan dan kuat tarik belah yang dihasilkan oleh beton dengan void minimal lebih tinggi, dibandingkan dengan beton normal maupun beton dengan void maksimal walaupun dengan perbedaan yang tidak signifikan.

\section{DAFTAR PUSTAKA}

[1] Tri Mulyono, 2003, “Teknologi Beton”, Departemen Pendidikan Nasional ,Direktorat Jendral Pendidikan Tinggi, Jakarta

[2] Anonim, 1998, "Metode Pengujian Bobot Isi dan Rongga Udara Dalam Agregat", SK SNI 03 - 4804 - 1998, Yayasan Penerbit Pekerjaan Umum, Jakarta

[3] I Made Agus Ariawan dan I.A Rai Widhiawati (2010) “ Pengaruh Gradasi Agregat Terhadap Karakteristik Campuran Laston” Jurnal Ilmiah Teknik Sipil Vol. 14, No. 2, Juli 2010.

[4] Beasman, L.E and McCuen, R.H. ( 2011) "Estimating the Distribution of Air Void in Concrete" Civil Engineering Dimension, Vol. 13, No.1, March 2011

[5] Karthik Obla, Haejin Kim, and Colin Lobo ( 2007 ) “Effect of Continous ( Well-Graded) Combined Aggregate Grading on Conrete Performance" Aggregate Voids Content (Packing Density) Project D340, May 2007.

[6] Jody Wall, P.E (2003) " Optimized 3/4 " Gradation Lightweight Aggregate Report " Carolina Stalite Company, January 2003.

[7] Sanchez-Leal, F.J, (2007) “Gradation Chart for Asphalt Mixes: Development” Journal of Materials in Civil Engineering, February 2007.

[8] ASTM C 29/C 29M - 97 ( Reapproved 2003 ) “ Standartd Test Method for Bulk Density ("Unit Weight”) and Void in Aggregate " ASTM International, West Conshohockhen,PA,2006, 4 pp.

[9] ASTM C 39/C 39M “ Standartd Test Method for Compressive Strength of Cylindrical Concrete Specimens " ASTM International, West Conshohockhen,PA,2006, 7 pp.

[10] ASTM C 127 - 04 “ Standartd Test Methodfor Density, Relative Density ( Specific Gravity), and Absorption of Coarse Aggregate" ASTM International, West Conshohockhen,PA,2006, 6 pp.

[11] ASTM C 128 - 04a “ Standartd Test Method for Density, Relative Density ( Specific Gravity ), and Absorption of Fine Aggregate" ASTM International, West Conshohockhen,PA,2006, 6 pp.

[12] ASTM C 136-06 " Standartd Test Method for Sieve Analysis of Fine and Coarse Aggregates " ASTM International, West Conshohockhen,PA,2006, 5 pp. 
[13] ASTM C 642 - 97 “ Standartd Test Method for Density, Absorption, and Void in Hardened Concrete “ ASTM International, West Conshohockhen,PA,2006, 3 pp.

[14] Departemen Pekerjaan Umum.LPMB, “ Tata Cara Pembuatan Campuran Beton Normal “. SK SNI T-15-1990-03

[15] J. Francis Young, David Darwin, Mindess Sidney, “ Concrete “, United States of America, 2002. 